\title{
MODIFIKASI DONGKRAK SCREW MEKANIS MENJADI DONGKRAK SCREW ELEKTRIK KAPASITAS 1 TON MENGGUNAKAN WIRELESS REMOTE CONTROL
}

\author{
Muchamad Masshuri \\ Teknik Mesin, Fakultas Teknik \\ Universitas Maarif Hasyim Latif, Sidoarjo Indonesia \\ e-mail : muchamad-masshuri@student.umaha.ac.id
}

\begin{abstract}
ABSTRAK
Dongkrak screw mekanis adalah suatu alat angkat yang dapat digunakan oleh pengemudi mobil saat terjadi kerusakan, terutama pada saat roda kendaraan bocor. Karena bentuk dan desain dongkraknya, maka tidak semua orang dapat dengan mudah memakai dongkrak ini terutama para wanita. Sehingga dilakukan pemodifikasian dongkrak screw mekanis menjadi dongkrak screw elektrik dengan menambahkan remote control. Dan pemodifikasian ini dapat mempermudah pekerjaan karena cepatnya proses pengangkatan mobil, serta tidak menimbulkan kelelahan karena melakukan gerakan yang sama berulang kali, cukup hanya dengan menekan tombol remote dan mobil pun bisa bergerak naik. Dan nantinya hasil modifikasi ini akan di uji cobakan pada mobil yang sesungguhnya. Pemodifikasian dongkrak ini dilakukan dengan cara menambahkan gearbox dan motor dc, dan remote control. Prinsip kerja dongkrak screw elektrik adalah putaran dari motor dc direduksi oleh gearbox dan diteruskan ke batang ulir pada dongkrak, dan mengirimkan sinyal pada modul remote control. Sedangkan berasal dari sumber tenaga baterai mobil itu sendiri. Bisa dengan cara dijepitkan langsung ke aki mobil, atau dicolokkan ke arus listrik yang ada pada dashboard mobil. Hasil perhitungan dan pengujian menunjukkan bahwa dongkrak screw hasil modifikasi dapat bekerja dengan baik, dengan gaya angkat sebesar $3048 \mathrm{~kg}$, dan rata - rata waktu angkat 39.5 detik dan tinggi angkat 28,2 cm, dengan tegangan rata- rata tanpa beban 3,24A dan dengan beban 7,15A
\end{abstract}

Kata Kunci: dongkrak, gearbox, limit switch,motor DC, remote control , saklar

\section{PENDAHULUAN}

Salah satu alat transportasi yang pada umumnya digunakan untuk menunjang bagi kehidupan manusia adalah mobil. Banyak orang menggunakan mobil untuk pergi liburan bersama keluarga, berkunjung ke tempat saudara, ke tempat kerja, ke sekolah, pergi berbelanja dan lain - lain. Mobil menggunakan tenaga mesin sebagai tenaga gerak. Seperti halnya mesin - mesin yang lainnya mobil dapat mengalami kerusakan selama masa penggunaan, sehingga memerlukan suatu pemeliharaan dan perbaikan.

Untuk memperbaiki kerusakan yang terjadi pada mobil khususnya kerusakan yang terjadi pada bagian bawah kendaraan dan pada roda-roda, biasanya membutuhkan bantuan sebuah alat pengangkat seperti dongkrak. Dongkrak merupakan sebuah salah alat pengangkat untuk mengangkat barang berat yang digerakkan menggunakan tangan atau kaki. Dongkrak berfungsi untuk mengangkat mobil, sehingga untuk perbaikan pada roda-roda kendaraan ataupun kerusakan pada bagian bawah kendaraan dapat dilakukan dengan mudah. Menurut cara kerjanya dongkrak dibedakan menjadi dua jenis yaitu dongkrak hidrolik dan dongkrak mekanis.

Berdasarkan uraian di atas perlu dikembangkan suatu alat pengangkat yang mudah dalam pengopersiannya. Sehingga dibuatlah penelitian tentang "MODIFIKASI DONGKRAK SCREW MEKANIS MENJADI DONGKRAK SCREW ELEKTRIK KAPASITAS 1 TON MENGGUNAKAN WIRELESS REMOTE CONTROL". Jadi, dongkrak ini dapat digunakan secara otomatis dan dikendalikan menggunakan remote control sehingga saat mengalami pecah ban apalagi ban mobil bocor di jalanan tidak perlu capek lagi untuk dongkrak mobil.

Tujuannya adalah untuk mempermudah pengoperasian menggunakan dongkrak itu sendiri. Untuk itu merencanakan suatu alat yang bisa meringankan atau membantu proses pengangkatan kendaraan yang efektif dan tidak membutuhkaan tenaga yang besar dengan salah satu cara penambahan motor listrik pada dongkrak screw sehingga siapapun nantinya dapat mudah untuk mengoperasikan dongkrak ini.

Berdasarkan batasan masalah di atas diperoleh satu rumusan masalah yaitu bagaimana cara memodifikasi dongkrak screw mekanik 
menjadi dongkrak screw elektrik. Dan kerusakan kerusakan yang terjadi pada kendaraan kita bisa jadi salah satu kurangnya perawatan dan juga karena musibah seperti terjadi kecelakaan atau bocornya ban pada kendaraan. Pada kendaraan bermotor untuk mengatasi masalah bocornya ban kendaraan dapat teratasi dengan mudah.

\section{METODE PENELITIAN}

Metodologi atau pendekatan yang akan dilakukan dalam penelitian ini adalah adalah dengan memodifikasi dongkrak mekanis yang biasa menjadi dongkrak elektrik dengan menambahkan wireless remote control untuk memudahkan pengguna dalam mengoperasikan dongkrak tersebut. Jenis dongkrak yang digunakan adalah dongkrak screw

Secara garis besar alur pelaksanaan penelitian ini dijelaskan pada flowchart dibawah ini

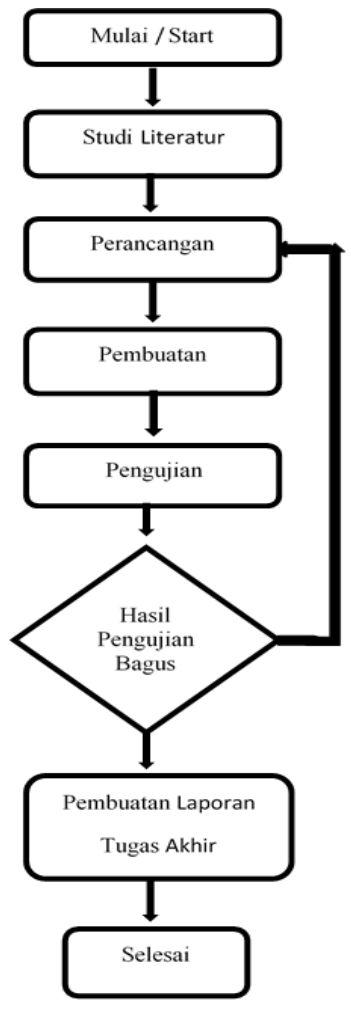

Gambar 1 Diagram Alur (Flow Chart)

\section{Pemilihan Dongkrak}

Pemilihan dongkrak dilakukan karena ada banyak jenis dongkrak dipasaran dan setiap jenis dongkrak memiliki kekurangan dan kelebihan untuk itu jenis dongkrak yang dipakai akan berpengaruh terhadap bentuk, sistem kerja dan cara memodifikasi dongkrak elektrik.

\section{Perencanaan Desain}

Saat mendesain suatu alat maka harus menentukan kriteria dari alat tersebut. Adapun kriteria dongkrak yang ingin di buat adalah sebagai berikut:

a. Kuat dan tahan lama sehingga akan mengurangi biaya perbaikan.

b. Komponen tidak banyak sehingga akan memudahkan perakitan dan pemeliharaan.

c. Kemampuan mengangkat semaksimum mungkin.

d. Biaya pembuatan murah.

e. Pengoperasian mudah.

\section{Menghitung Beban Motor}

Perhitungan terhadap beban motor dilakukan agar nantinya saat pengadaan komponen akan memudahkan dalam mencari jenis motor yan tepat untuk penggerak dongkrak. Perhitungan ini dilakukan dari beban yang dibutuhkan dongkrak hingga sampai pada roda gigi pada motor penggerak.

\section{Pengadaan Komponen}

Komponen - komponen yang akan dipakai dalam mengerjakan modifikasi dongkrak ini adalah:

a. Dongkrak screw

b. Motor DC

c. Kabel Penghubung

d. Roda gigi (gear)

e. Remote control

5. Rekayasa Rangkaiaan Kontrol

Rangkaian kontrol berfungsi untuk mengontrol gerakan dongkrak saat naik dan turun maka untuk membalikkan putran maka dibuatlah sebuah rangkaian agar motor dapat mudah balik putrannya.

\section{Perakitan (assembli)}

Menggabungkan semua komponen dan melakukan finishing

\section{Pengujian fungsi}

Tahap ini dilakukan untuk mengecek apakah alat telah berfungsi dengan baik jika belum berfungsi maka di perbaiki kembali jika sudah berfungsi maka memodifikasi dongkrak selesai dilakukan.

\section{Pembuatan Laporan Tugas Akhir}

Membuat laporan dari apa yang telah dikerjakan dalam memodifikasi dongkrak screw mekanik menjadi dongkrak screw elektrik.

\section{Konsultasi Pembimbing}

Melakukan bimbingan tugas akhir untuk bab 4 pembahasan dan bab 5 penutup

\section{Alat dan Bahan}

Pembuatan tugas akhir ini mencakupi alat dan bahan yang akan digunakan. Adapun alat dan bahan yang digunakan adalah:

1. Alat 
Peralatan utama yang digunakan dalam pengerjaan alat ini antara lain: Mesin konvensional, alat-alat perkakas Dan alat ukur seperti:
a. Alat solder
b. Kunci inggris
c. Gunting
d. Pisau
e. Tes pen
f. Obeng plus
g. Obeng minus
h. Tang buaya

2. Bahan

Selain komponen - komponen yang terdapat pada dongkrak itu sendiri terdapat juga bahan- bahan pendukung yang digunakan dalam pemodifikasian dongkrak tersebut, diantaranya adalah :
a. Timah (solder)
b. Solasi
c. Kabel Penghubung

\section{HASIL DAN PEMBAHASAN}

Dalam penelitian ini penulis memilih dongkrak screw mekanis yang akan dimodifikasi menjadi dongkrak screw elektrik dengan menambahkan wireless remote control.

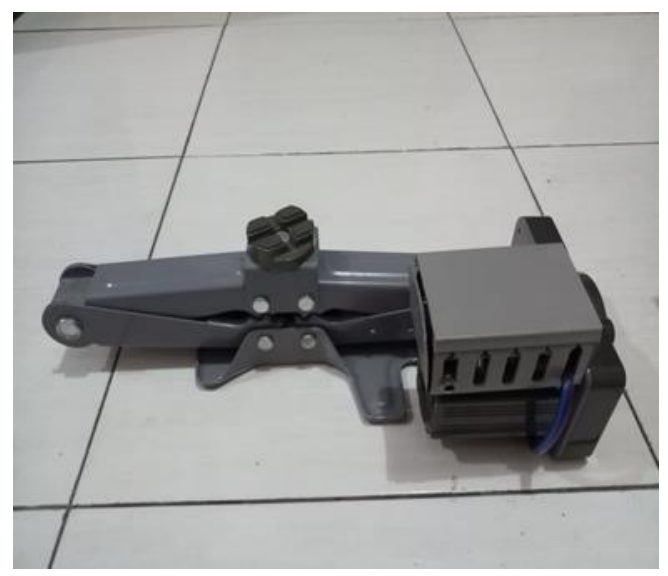

Gambar 2. Dongkrak screw

Kelebihan dongkrak screw adalah harganya murah, perawatan mudah, parktis dan tidak banyak memakan tempat, Dongkrak screw dipakai untuk dimodifikasi dikarenakan beberapa alasan, dongkrak screw akan naik jika diputar ke kanan dan jika diputar ke kiri maka akan turun. Dibandingkan dengan dongkrak hidrolik, dongkrak screw lebih mudah dalam penyimpanan, perawatan dan pengoperasian, juga lebih praktis bias dibawa kemana - mana.

Dalam memodifikasi dongkrak screw mekanik menjadi dongkrak screw elektrik dengan menambahkan wireless remote control dilakukan beberapa tahapan antara lain:
1. Memilih dongkrak yang akan dimodifikasi. Dalam penelitian atau pemodifikasian kali ini penulis akan memodifikasi dongkrak screw

2. Memasang komponen yang meliputi dongkrak screw, transmisi (gearbox), motor arus searah (DC) dan remote control

3. Menyeting kedudukan antara poros dongkrak screw terhadap poros transmisi dan poros motor arus searah (DC).

4. Jika kedudukan sudah berada pada posisi center, maka dilakukan pemasangan kabel pada gearbox control posisi untuk mengubah putaran dari motor arus searah (DC).

5. Setting remote pada modul.

6. Pemasangan kerangka atas, lalu merangkai kabel yang nantinya dihubungkan ke colokan arus listrik yang ada pada dashboard mobil.

7. Selain merangkai kabel penghubung ke colokan dashboard, ada juga kabel jumper ke aki

8. Selanjutnya dilakukan uji coba dongkrak screw elektrik dan finishing.

9. Dalam uji coba kali ini penulis akan menguji dongkrak screw yang telah dimodifikasi tersebut pada mobil avanza type s

Berikut ini adalah gambar dari dongkrak screw botol yang akan dimodifikasi.

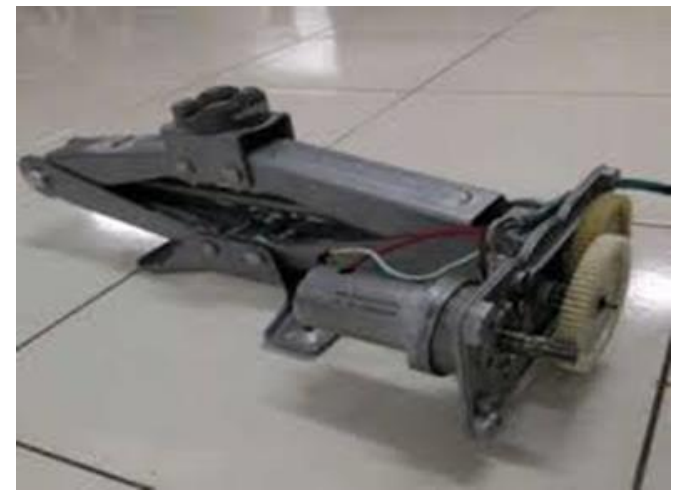

Gambar 3. Dongkrak screw yang akan dimodifikasi

\section{Perhitungan gaya angkut yang dihasilkan}

Setelah mendapatkan desain selanjutnya dilakukan perhitungan pada sub ini akan dihitung besar gaya angkut $(\mathrm{F})$

1. Data -data yang diketahui / pengukuran

a. Torsi Motor DC sebesar $300 \mathrm{Kgcm}\left(\mathrm{T}_{1}\right)$

b. Sistem diasumsikan tanpa gesekan.

c. Lengan pengangkat $6,5 \mathrm{~cm}(\mathrm{R})$

d. Jumlah gigi pada Gear wheel dongkrak 68 buah $\left(\mathrm{Z}_{2}\right)$

e. Jumlah gigi pada gear pinion dongkrak 7 buah $\left(\mathrm{Z}_{1}\right)$

f. Jumlah gigi pada gear poros 68 buah (Z)

g. Jumlah gigi pada gear motor 10 buah $\left(Z_{3}\right)$ 
2. Besarnya torsi yang dihasilkan dapat dihitung dengan persamaan sbb:

$$
\begin{aligned}
& T_{1}=\frac{T_{2} Z_{2} Z_{4}}{Z_{1} Z_{3}} \\
& T_{2}=\frac{300 \mathrm{Kgcm} \cdot 68.68}{7.10} \\
& T_{2}=19817 \mathrm{Kg} f
\end{aligned}
$$

Jadi, Torsi yang dihasilkan sebesar 19817 Kgf Besarnya gaya angkut yang dihasilkan sbb: Diketahui

$$
\begin{gathered}
T_{2}=F x R \\
F=\frac{T_{2}}{R}
\end{gathered}
$$

Dimana :

$\mathrm{T}=$ Torsi $(K g f)$

$\mathrm{F}=$ Gaya $(\mathrm{Kg})$

$\mathrm{R}=$ Jari - Jari Penampang $(\mathrm{cm})$

Maka,

$$
\mathrm{F}=\frac{T_{2}}{R}
$$

$$
\mathrm{F}=\frac{19817 \mathrm{kgcm}}{6,5 \mathrm{~cm}}
$$

$\mathrm{F}=3048 \mathrm{Kg}$

Jadi diketahui besar gaya angkat dongkrak sebesar $\underline{3048} \mathrm{Kg}$

\section{Komponen - Komponen Dongkrak screw modifikasi}

Komponen- komponen tersebut harus ada, jika ada salah satu komponen saja yang tidak terpenuhi maka alat yang dimodifikasi tersebut bisa jadi tidak sesuai dengan apa yang menjadi tujuan yang dimaksudkan.

Pada tabel berikut ini adalah daftar komponen komponen yang menjadi bagian dari dongkrak screw yang dimodifikasi, baik komponen standar (yang sudah ada di pasaran) maupun komponen tambahan:

Tabel 1. Komponen - komponen yang diperlukan

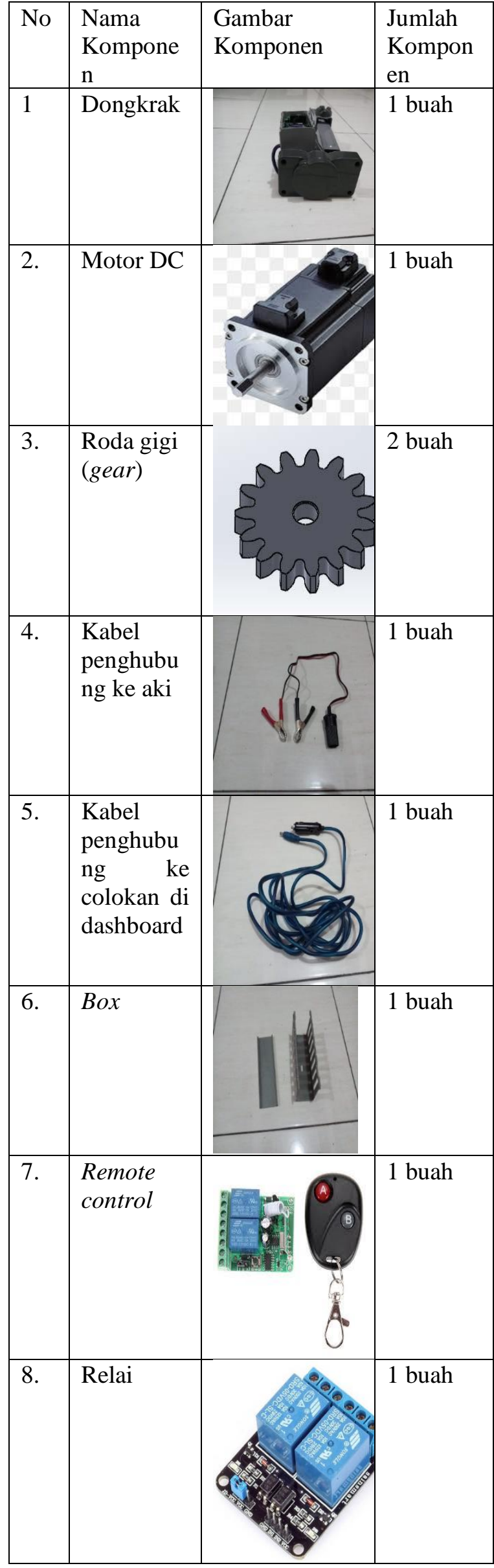




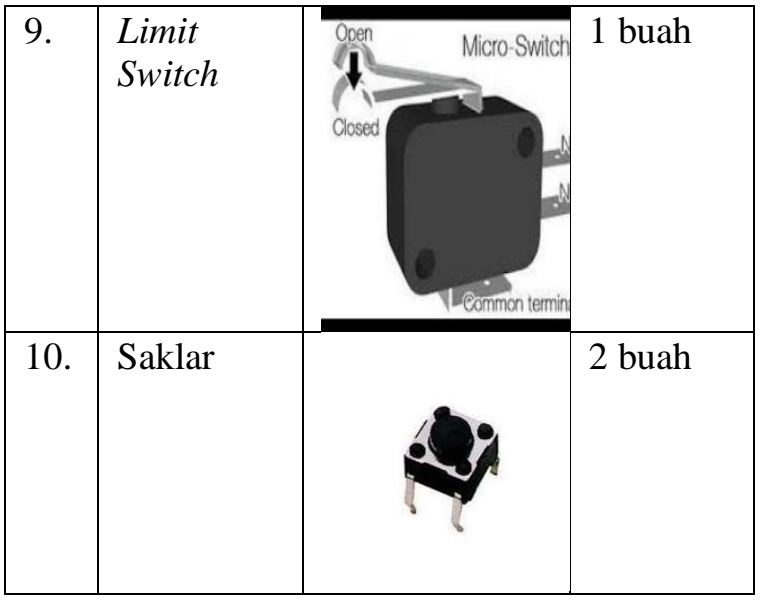

Selain komponen - komponen yang terdapat pada tabel diatas, dalam memodifikasi dongkrak screw ini juga memerlukan beberapa alat atau benda yang dipakai dalam memodifikasi atau merakit dongkrak screw mekanik menjadi dongkrak screw elektrik tersebut, sehingga menghasilkan alat yang sesuai dengan apa yang menjadi tujuan dalam memodifikasi alat tersebut.

Berikut ini adalah tabel daftar alat yang diperlukan dalam memodifikasi dongkrak screw mekanik menjadi dongkrak screw elektrik ini sehingga bisa dijalankan dengan menggunakan remote control:

Tabel 2 Alat - alat yang diperlukan

\begin{tabular}{|l|l|l|l|l|}
\hline No & $\begin{array}{l}\text { Nama } \\
\text { alat }\end{array}$ & \multicolumn{2}{|l|}{ Gambar alat } & $\begin{array}{l}\text { Jumlah } \\
\text { alat }\end{array}$ \\
\hline 1 & $\begin{array}{l}\text { Solder } \\
\text { dan } \\
\text { timah } \\
\text { solder }\end{array}$ & & 1 buah \\
\hline 2. & Obeng & & \\
\hline 3. & Tes pen & & \\
\hline
\end{tabular}

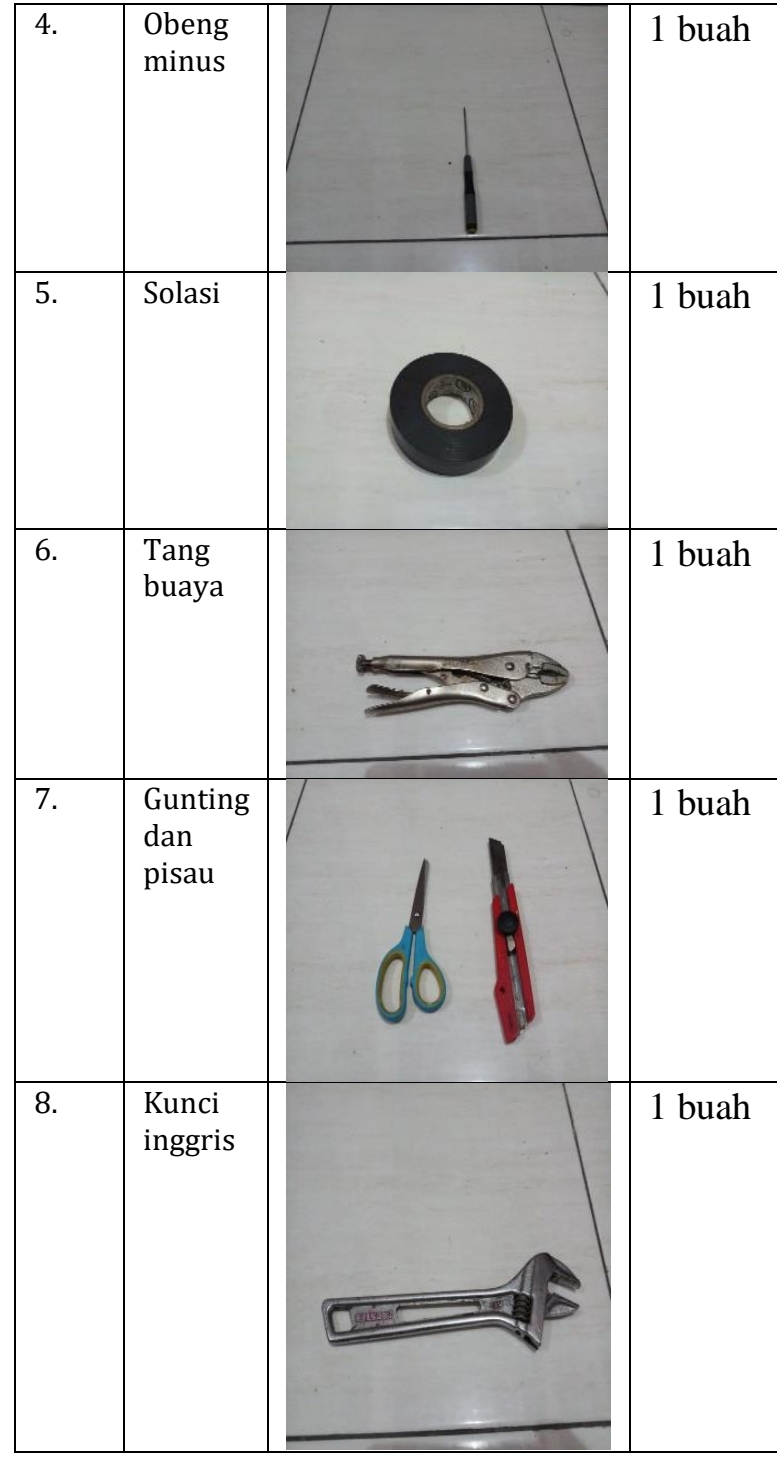

\section{Proses Assembling (Perakitan)}

Pada proses assembling (perakitan) semua komponen - komponen mesin digabungkan secara utuh sehingga terbentuklah suatu mesin yang sudah direncanakan dan siap pakai. Proses penggabungan harus dilakukan dengan benar agar setiap komponen dapat terpasang dengan baik dan tidak terjadi kerusakan saat memasang komponen.

Dalam memodifikasi dongkrak screw mekanik menjadi dongkrak screw elektrik dengan menggunakan wireless remote control ini, dilakukan beberapa tahapan diantaranya adalah:

1. Memasang komponen yang meliputi dongkrak screw, transmisi (gearbox), motor arus searah (DC) dan remote control.

2. Menyeting kedudukan antara poros dongkrak screw terhadap poros transmisi dan poros motor arus searah (DC). 
3. Selanjutnya dilakukan pemasangan kabel pada modul remote control

4. Pemasangan kerangka box atas, lalu merangkai dengan menyolder kabel yang nantinya dihubungkan pada colokan charge mobil (lighter) yang ada pada dashboard mobil dan aki yang ada pada kap mobil

5. Selanjutnya dilakukan uji coba dongkrak screw elektrik hasil modifikasi dan finishing.

Berikut ini adalah gambar dari dongkrak screw yang sudah selesai dimodifikasi.

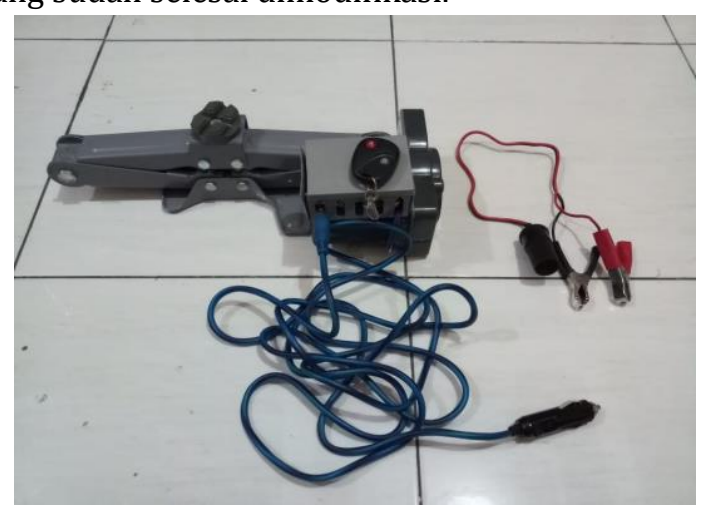

Gambar 4. Dongkrak screw yang telah dimodifikasi

\section{Pengujian}

Pada penelitian kali ini akan diadakan pengujian dongkrak screw elektrik yang telah dimodifikasi. Dalam pengujian kali ini mobil yang dipakai adalah mobil avanza type s yang mempunyai berat $1045 \mathrm{~kg}$. Dan berdasarkan perhitungan mobil tersebut akan mampu diangkat oleh dongkrak screw elektrik hasil modifikasi.

Berikut ini adalah tabel hasil pengujian dongkrak screw elektrik hasil modifikasi:

Tabel 3. Hasil pengujian dongkrak elektrik

\begin{tabular}{|c|c|c|c|c|}
\hline No & Wakt & Ketinggia & \multicolumn{2}{|c|}{ Ampere } \\
\cline { 4 - 5 } & $\begin{array}{c}\text { u } \\
\text { angka } \\
\mathrm{t} \\
(\text { detik } \\
\text { ) }\end{array}$ & & $\begin{array}{c}\text { Tanp } \\
\mathrm{a} \\
\text { beban }\end{array}$ & $\begin{array}{c}\text { Denga } \\
\mathrm{n} \\
\text { beban }\end{array}$ \\
\hline 1. & 40 & 28.5 & 3,3 & 7,2 \\
\hline 2. & 40 & 28 & 3,2 & 7,2 \\
\hline 3. & 39 & 28 & 3,2 & 7,1 \\
\hline 4. & 40 & 28.5 & 3,3 & 7,1 \\
\hline 5. & 40 & 29 & 3,3 & 7,2 \\
\hline 6. & 40 & 28 & 3,2 & 7,2 \\
\hline 7. & 39 & 28 & 3,2 & 7,1 \\
\hline 8. & 38 & 27.5 & 3,2 & 7,1 \\
\hline
\end{tabular}

\begin{tabular}{|c|c|c|c|c|}
\hline 9. & 39 & 28 & 3,2 & 7,1 \\
\hline 10. & 40 & 28.5 & 3,3 & 7,2 \\
\hline $\begin{array}{c}\text { Rata } \\
\text { - rata }\end{array}$ & $\mathbf{3 9 . 5}$ & $\mathbf{2 8 , 2}$ & $\mathbf{3 . 2 4}$ & $\mathbf{7 , 1 5}$ \\
\hline
\end{tabular}

Jadi, dari tabel diatas diketahui bahwa dari hasil pengujian dongkrak ulir (screw) hasil modifikasi mempunyai rata - rata waktu angkat 39,5 detik dan ketinggian angkat 28,2 cm dengan ampere 3,24 A (tanpa beban) dan 7,15A (dengan beban)

\section{PENUTUP}

1. Dongkrak screw elektrik hasil modifikasi dapat dioperasikan dengan baik, dan berhasil mengnakat mobil avanza type $\mathrm{S}$

2. Besarnya gaya angkat yang dihasilkan oleh dongkrak elektrik sebesar $3048 \mathrm{~kg}$

3. Waktu yang dibutuhkan untuk mengangkat lebih cepat dapat mewujudkan hasil pengujian menunjukkan waktu angkat sebesar 39,5 detik dengan ketinggian $28,2 \mathrm{~cm}$

4. Tegangan yang dibutuhkan rata - rata tanpa beban 3,24A dan dengan beban 7,15A

\section{UCAPAN TERIMA KASIH}

Dalam kesempatan ini pula kami menyampaikan terima kasih dan penghargaan yang sebesar besarnya atas segala bimbingan dan bantuan selama menyelesaikan tugas akhir ini kepada :

1. Bapak Dr. H. Achmad Fathoni Rodli, M.Pd selaku Rektor Universitas Ma'arif Hasyim Latif Sidoarjo

2. Bapak Drs. Moch. Hatta, MT selaku Dekan Fakultas Teknik Universitas Ma'arif Hasyim Latif Sidoarjo

3. Bapak Prof. Dr. Rusijono, M.Pd Selaku Kepala Prodi Teknik Mesin Universitas Ma'arif Hasyim Latif Sidoarjo.

4. Bapak Ir. Suhariyanto, MSc Selaku Dosen Pembimbing dalam penyelesaian skripsi ini dari Universitas Ma'arif Hasyim Latif Sidoarjo.

5. Teman-teman Jurusan Teknik Mesin Umaha khususnya angkatan 2015/2016 yang selalu memberikan saran dan semangat kepada penulis dalam menyusun laporan ini.

6. Untuk keluarga besarku, khususnya ibuku yang tak pernah lelah mendoakanku

7. Tak lupa untuk keluargaku tercinta, khususnya istriku Nur Indah A'isah dan kedua putra solehku Muhammad Adzka Nafi' Mubarok dan Muhammad Raffasya Abqary, kalian adalah penyemangat hidupku. 


\section{DAFTAR PUSTAKA}

Affandi, I. (2009). Analisa Seting Relai Arus Lebih dan Relai Gangguan Tanah Pada Penyulang Sadewa DiGicawang. Depok.

Akbar, N. I. (2016). Modifikasi dongkrak mekanik menjadi elektromekanik kapasitas 2 ton. Universitas pasundan bandung.

Arafat, Y. \& M. (2015). Dongkrak Mobil Otomatis Bantu Pemilik Mobil.

Fitra, R. (2017). Modifikasi Dongkrak Ulir Menjadi Dongkrak Ulir Elektrik. politeknik Negeri Padang.

Laksono, S. (2017). Perencanaan modifikasi dongkrak ulir botol menjadi dongkrak elektrik. Universitas nusantara pgri kediri.

Pambudi, A. A. (2016). Dongkrak Elektrik Dengan Kontrol Smartphone Android Menggunakan Media Koneksi Bluetooth. Universitas Kristen Satya Wacana Salatiga.

Pandoyo, T. G. (2013). Perencanaan Gearbox Dan Perhitungan Daya Motor Pada Modifikasi Dongkrak Ulir Mekanis Menjadi Dongkrak Ulir Elektrik. Universitas Lampung.

Sularso. (1991). Dasar -Dasar Perencanaan Dan Pemilihan Elemen Mesin. Jakarta: Pradnya Paramita.

Wijaya, H. S. (2014). Rancang Bangun dongkrak Gunting Elektrik Pada Mobil. Politeknik Negeri Sriwijaya Palembang.

Yunianto, A. (2017). Modul Limit Switch Dan Sensor Pada Pneumatik Dan Elektro Pneumatik. 
M Masshuri / Mechonversio, Vol. 2, No.2, Desember 2019, 63-70

Halaman ini sengaja dikosongkan 